\title{
A Ecossocioeconomia e o Bem Viver na perspectiva do Urbano
}

\author{
La Ecossocioeconomia y el Bien Vivir en la perspectiva Urbana \\ Ecossocioeconomia and Well Live from the perspective of the urban
}

\author{
Dra. Liliane Cristine Schlemer Alcântara' ${ }^{1}$ \\ Dra. Isabel Jurema Grimm²
}

\begin{abstract}
Resumo
Contemporaneamente, a mobilidade representa um dos principais desafios que as cidades enfrentam na tentativa de alcançar o desenvolvimento sustentável, integrando alternativas para aperfeiçoar o deslocamento de pessoas, mercadorias e promover o bem viver urbano. Assim, o objetivo deste artigo é dialogar sobre o tema da ecossocioeconomia a partir da relação dialética do bem viver. Trata-se de um ensaio bibliográfico-exploratório que sistematiza um conjunto de esforços compreendidos entre revisão da literatura dos temas em questão e pesquisa de campo para apresentar uma análise comparativa que trata da mobilidade urbana, com foco no uso da bicicleta em três casos reconhecidos: as cidades de Amsterdã, Copenhague e Rio de Janeiro. Como resultados temse os indicadores ecossocioeconômicos utilizados para mensurar a motivação para o uso da bicicleta; ações, investimentos e infraestrutura cicloviária existentes; políticas públicas de incentivo e de educação para o uso da bicicleta; índice de sustentabilidade do modal e projetos futuros.
\end{abstract}

Palavras-Chave: Cidades; Desenvolvimento Sustentável; Mobilidade Urbana.

\section{Resumen}

Contemporáneamente, la mobilidad representa uno de los principales desafíos que las ciudades enfrenta en el intento de alcanzar el desarrollo sostenible, integrando alternativas de desplazamiento de personas, mercancías y promover el bien vivir urbano. Así, el objetivo de este artículo es dialogar sobre el tema de la ecosocioeconomía a partir de la relación dialéctica del bien vivir. Se trata de un ensayo bibliográfico-exploratorio que sistematiza un conjunto de esfuerzos comprendidos entre revisión de laliteratura e investigación de campo para presentar un análisis comparativo que trata de la mobilidad urbana, con foco en el uso de la bicicleta en tres casos reconocidos: las ciudades de Ámsterdam, Copenhague y Río de Janeiro. Como resultados se tienen los indicadores ecosocioeconómicos utilizados para medir la motivación para el uso de la bicicleta; acciones, inversiones e infraestructura de ciclo de vida existentes; políticas públicas de incentivo y de educación para el uso de la bicicleta; índice de sostenibilidad del modal y proyectos futuros.

Palabras claves: Ciudades; Desarrollo Sostenible; Mobilidad Urbana.

\begin{abstract}
This document contains information on the preparation of the final version of a paper accepted for publication in the Revista RELACult. Please carefully follow the instructions provided to ensure legibility and uniformity of accepted papers

Keywords: Cities; Sustainable Development; Urban Mobility.

\footnotetext{
${ }^{1}$ Pós-doutorado em Gestão Urbana pela Pontifícia Universidade Católica do Paraná (PUC-PR). Doutora em Desenvolvimento Regional pela Universidade Regional de Blumenau (FURB/SC). Bacharel em AdministraçãoSETREM/RS. E-mail: lilianecsa@yahoo.com.br.

${ }^{2}$ Pós-doutorado em Gestão Urbana pela Pontifícia Universidade Católica do Paraná (PUC-PR). Doutora em Meio Ambiente e Desenvolvimento pela Universidade Federal do Paraná (UFPR). Bacharel em Turismo pela UNIOESTE (Foz do Iguaçu). E-mail: isabelgrimm@gmail.com.
} 


\section{Introdução}

O conceito de desenvolvimento associado aos países do "primeiro mundo" tem ocasionado inúmeros impactos ambientais, alterando os ciclos da natureza como mudanças climáticas, emissão de gases poluentes, contaminações e outros.

A lógica acumulativa levou muitas pessoas a migrar para as cidades, em busca de progresso na perspectiva de uma "vida melhor". Este fenômeno acabou desintegrando culturas milenares e o crescimento das áreas urbanas, gerando problemas de saúde, falta de habitação, trabalho, aumento da pobreza, marginalidade e desigualdade socioeconômica.

Contemporaneamente, as cidades enfrentam desafios na tentativa de alcançarem o desenvolvimento sustentável. De acordo com (Ornés 2010, p. 17), a sustentabilidade urbana pode ser compreendida como um modelo de bom desempenho, equilíbrio e conectividade entre as dimensões do desenvolvimento visando um ambiente produtivo, eficiente, inclusivoequitativo, seguro e saudável, possibilitando a satisfação das necessidades presentes e futuras. $\mathrm{Na}$ cidade, a comunidade é o recurso principal do território, lócus do desenvolvimento e onde se tornam necessárias ações sociais que possam mediar os interesses privilegiando a convivência e o bem viver.

Para compreender melhor a questão do bem viver associado ao urbano, é importante considerar que cada sistema econômico, social e político adota métodos diferentes para a satisfação das necessidades humanas e a escolha de satisfatores. Essa escolha tem relação direta com o tipo de desenvolvimento adotado localmente, servindo como influenciador direto na criação e formulação de políticas públicas para a satisfação das diversas necessidades da população.

Nesta conjectura, surge um modelo alternativo ao desenvolvimento que procura romper com as lógicas antropocêntricas do capitalismo, civilização dominante e também os diversos socialismos existentes até agora. Ao mesmo tempo, propõe uma mudança rumo a um mundo que seja sustentável, justo, igualitário, livre e mais humano. A este modelo, denomina-se ecossocioeconômico com base nos preceitos do bem viver.

A ecossocioeconomia emerge como uma concepção pragmática, na qual experimentações com diferentes gêneses, apresentam alternativas de soluções engenhosas, no que se refere a tecnologias apropriadas ao local e ou arranjos institucionais e produtivos, associada a experiências territoriais contemporâneos e, podem ser caracterizadas tanto como mitigadoras quanto adaptativas as mudanças climáticas (SAMPAIO et al., 2017). A ecossocioeconomia privilegia modos de vidas caracterizadas como tradicionais, onde o bem 
viver está intimamente relacionado ao cotidiano destas comunidades, pois elas mantem uma relação de proximidade com a natureza e tudo que as cerca.

Diante disso, o objetivo deste artigo é dialogar sobre o tema da ecossocioeconomia a partir da relação dialética do bem viver. Trata-se de um ensaio bibliográfico que sistematiza um conjunto de esforços compreendidos entre revisão da literatura dos temas em questão e pesquisa de campo para apresentar uma análise comparativa que trata da mobilidade urbana, com foco no uso da bicicleta.

Metodologicamente, trata-se de uma pesquisa exploratória de três casos reconhecidos: as cidades de Amsterdã (Holanda), Copenhague (Dinamarca) e Rio de Janeiro (Brasil). A coleta de dados baseou-se na observação de campo realizada nas regiões centrais e turísticas destas cidades que fazem uso da bicicleta, como alternativa de locomoção pela população e visitantes. O referencial teórico tem como base a pesquisa bibliográfica-exploratória com interpretação e análise crítica dos temas.

\section{Aporte teórico conceitual}

\subsection{Desenvolvimento e sustentabilidade: para pensar a vida nas cidades}

Nas últimas décadas, é visível um aumento da tomada de consciência em relação aos problemas socioambientais que surgem como desafios à sociedade contemporânea. Pensar em mudanças que possam resultar na melhoria da qualidade de vida da população e a orientação para a preservação do meio ambiente requer que se tenha conhecimento tanto dos problemas quanto dos processos naturais do ambiente em que vivemos.

Neste contexto, a mobilidade urbana baseada em soluções motorizada e individual de transporte é cada vez mais presente no dia a dia das cidades e vêm pressionando governos na busca de alternativas a este modal. Decisores políticos tem como desafio expandir a quota de modos de transporte sustentáveis, integrando diversas iniciativas para aperfeiçoar o deslocamento de pessoas, mercadorias e promover o bem viver urbano.

Entretanto, o transporte que se encontra sobrecarregado sobretudo nos centros urbanos, tem agravado a poluição atmosférica e sonora, diminuído os níveis de segurança e impactado a vida social, econômica e ecológica. Em alguns casos, os sistemas de transporte público e facilidades para usuários de transporte alternativo como a bicicleta, são particularmente propensos à negligência, falta de estrutura e de políticas públicas de mobilidade alternativa (GTZ, 2011). Usuários que contam com estes sistemas correm riscos por conta da má gestão da mobilidade urbana, e tendem a agravar-se na ocasião que há expansão do processo de 
desenvolvimento, o que pode sugerir aumento de frota de veículos, e consequentemente o aumento de níveis de gases nocivos de efeito estufa (GEE).

Um novo modelo de desenvolvimento que configure na equidade e na justiça social, deve partir da ação efetiva que posso como sugere Costa (2008), contribuir para solucionar a gravidade dos problemas socioambientais e, neste contexto a implantação de novos modais de transporte vem se destacando, visando melhor utilização das características das vias urbanas e melhor utilização desses recursos.

Muitas são as experiências em curso que sinalizam para a possibilidade de se pensar em alternativas de desenvolvimento ecossocioeconômico e bem viver, voltadas para ações territorializadas. A exemplo, cidades como Rio de Janeiro, Amsterdã e Copenhague são indicativos de que outros modais de transporte são possíveis e podem ser uma resposta a necessidade de mobilidade urbana sustentável, por meio da promoção de políticas públicas que incentivem o uso da bicicleta como meio de locomoção.

No caso brasileiro o uso da bicicleta está associado a estrutura de marcos legais que criam as condições conceituais e legais para os investimentos públicos na mobilidade, mas o poder público não tem promovido as "necessárias políticas públicas que fariam com que o uso de bicicletas se consolidasse com a devida prioridade e legitimidade, acompanhando o desenvolvimento das cidades brasileiras" (GUTH, 2016, p. 242).

Neste cenário, Costa (2005) aponta que novos modais de transporte devem ser prioridades na gestão das cidades visando melhor utilização das características das vias urbanas e melhor utilização desses recursos.

A inclusão de novos modais no sistema de transporte urbano, constitui-se como mitigadoras dos problemas de poluição ambiental e sonora, oferecendo maior qualidade de vida aos moradores, promovendo o bem viver nas cidades, onde de acordo com Falu e Marengo (2004), os principais desafios estão relacionados aos crescentes níveis de segregação social, melhor distribuição da oferta de serviços públicos e maior eficiência na dinâmica urbana possibilitando maior qualidade dos espaços.

Pereira (2006) afirma que para converter as cidades em territórios amigáveis, democráticos, saudáveis e sustentáveis, recuperando a escala humana, favorecendo à vida social plena para todos os cidadãos é preciso antes ressignificar os modais não motorizados, dando ênfase as alternativas de mobilidade. Portanto, compreender a comunidade urbana como cerne da ação e garantir o bem viver é o principal objetivo de uma estratégia de desenvolvimento humanizada. 
A mobilidade constitui-se elemento fundamental para a viabilização de novas políticas públicas no âmbito do desenvolvimento e do planejamento das cidades. Pensar em alternativas ao modelo de desenvolvimento vigente, passa pela democratização do espaço urbano e, neste contexto, propõe-se pensar em alternativas ecossocieconômicas, abrindo espaço para um novo enfoque sobre o tema, buscando a superação do planejamento que produz a necessidade de deslocamentos somente por meio de modos motorizados pelo incentivo a alternativas menos poluentes como pode ser o uso da bicicleta.

Neste momento, é cabível afirmar que propostas de desenvolvimento denominadas ecossocieconômicas, vem colaborar para a promoção de formas alternativas de viver, pautadas nos princípios da equidade intergeracional, onde as ações presentes poderão determinar como as gerações futuras irão viver. Portanto, pensar a ecossocioeconomia é pensar em uma categoria da filosofia de vida das sociedades indígenas ancestrais, estabelecendo uma cosmovisão diferente da visão ocidental ao surgir de raízes comunitárias não capitalistas: o bem viver.

O bem viver e a ecossocioeconomia como proposta de desenvolvimento, é entendido como uma maneira de visualizar as vulnerabilidades socioeconômicas e ambientais das comunidades, ancorada no conhecimento e saberes e numa nova forma de convivência, em diversidade e harmonia com a natureza que promovem uma crítica substancial à própria ideia de desenvolvimento.

Em sentido mais amplo a estratégia do desenvolvimento deve evidenciar a necessidade da manutenção e preservação da vida, devendo promover a harmonia entre a natureza e o homem, assegurando a efetiva participação; a geração de tecnologia de baixo impacto e a garantia dos princípios de equidade, solidariedade e dignidade do ser humano. Assim, alternativas teóricas, como as propostas de ecodesenvolvimento, desenvolvimento sustentável e da ecossocioeconomia, ganham força e derivações.

A ecossocioeconomia, que se postula no enfoque metodológico-empírico, vislumbra ações que permeiam o cotidiano de pessoas simples, que valorizam os seus "saberes" e "fazeres", visando criar possibilidades para que elas se deem conta de sua importância e de que são responsáveis pelo processo de construção de seu desenvolvimento, fazendo-os mais críticos e conscientes de sua realidade e transformando-se em sujeitos ativos da ação (GRIMM et al., 2016). Neste ponto, é cabível propor que estas ações podem constituir-se em postulados do bem viver, pois é a comunidade que pode e deve decidir que desenvolvimento desejam para seus territórios.

\subsection{Ecossocioeconomia: princípios para um outro desenvolvimento}


A ecossocioeconomia expõe a necessidade de constituir uma enciclopédia do cotidiano, a partir da sistematização de experimentações, que muitas vezes fica relegada ao mundo da vida, nos territórios, nas comunidades, nos povoados, nas organizações, onde problemas e suas soluções ocorrem e raramente são devidamente qualificados (SAMPAIO, 2010).

Os termos ecossocioeconomia, ecodesenvolvimento e desenvolvimento sustentável, podem ser considerados como derivativos da obra de Karl William Kapp (1950), na qual trata sobre custos socioambientais das empresas, o que atualmente se denomina como externalidade, o que implica na crítica à lógica de privatizar lucros de curto prazo e socializar custos socioambientais de médio e longo prazo, além de relacionar esta visão com questões estruturais, como Estado, mercado e sociedade civil bem como seus imbricamentos, tal como sugere a economia institucional.

O enfoque ecossocioeconômico pode ser aplicado também no contexto organizacional. A ecossocioeconomia das organizações apresenta três características, que podem ser chamadas de princípios, que estão imbricados entre eles: (i) viabilidade interorganizacional, no qual releva atores sociais mesmo com diversos graus de articulação na gestão organizacional; (ii) ação extraorganizacional, isto é, o agente organizacional relevando os impactos de sua ação sobre o entorno territorial; e (iii) extrarracionalidade nos processos de tomada de decisão, considerando a dimensão tácita do conhecimento dos grupos organizados (associações e cooperativa) ou quase organizados (movimentos sociais e grupos produtivos).

A dimensão ecossocioeconômica privilegia dimensões que valorizam a preservação de tradições e relações sociais mais solidárias; a geração de trabalho e renda sob a perspectiva de modos de produção e de distribuição mais associativistas; o revigoramento dos significados de virtude humana e do próprio Estado, distanciado do racionalismo utilitarista e, utilização adequada dos recursos naturais e das habilidades humanas locais (SAMPAIO, 2005).

Diante de sua concepção pragmática, o enfoque ecossocioeconômico é realizado no contexto territorial. Faz sentido, então, denominar ecossocioeconomia territorial, que possibilita pensar o território a partir da rede de agentes sociais que atuam nele e que os resultados/impactos da governança/gestão desses transbordem para além das fronteiras territoriais, o que se denomina de efetividade extraterritorial, além de relevar a chamada extrarracionalidade nos processos de decisão territorial, que podem se constituir de saberes e práticas cotidianas bem compreendidas em dado território, mas que podem ser de difícil entendimento fora dele.

Aproxima-se do que Polany (1983) denomina como dimensão tácita do conhecimento. A ecossocioeconomia territorial privilegia os estudos que possibilitam a viabilidade macro 
(interterritorial) e microeconômica (territorial) de pessoas e grupos organizados ou quase organizados articulados, chamados de socioempreendimentos compartilhados (SAMPAIO, 2010).

A ecossocioeconomia não exclui as iniciativas individuais socioprodutivas, entretanto, observam-se que as experiências paradigmáticas, ditas mais sistêmicas, com maior possibilidade de resultados consistentes e duradouros, são aquelas que estão estruturadas em arranjos institucionais e/ou socioprodutivos, ou que, ainda, Etzioni (2015) compreende por "the new normal" quando sociedades passam por crises, podendo ser sociopolítica, socioeconômica e socioecológica, que a partir delas alteram-se padrões de conduta ou comportamento da sociedade.

Diante disso, refere-se a ecossocioeconomia territorial, na qual as iniciativas se entrelaçam, como arranjos produtivos, onde há eminência de uma ação extraterritorial, isto é, o agente territorial absorvendo os impactos de sua ação além do entorno espacial delimitado por fronteiras físicas, no sentido de acordos institucionais, pensados como acordos sociopolíticos e socioprodutivos de base territorial, de modo que gerem capital social ${ }^{3}$ (SAMPAIO, 2010).

Tendo-se por base os princípios da ecossocioeconomia territorial, sugere-se que a gestão de empresas, organizações públicas, organizações não governamentais, bem como o arranjo interterritorial que é composto por esses três tipos de esferas de agentes devam ser pautados por critérios extraterritoriais, no sentido de incorporar demandas socioambientais oriundas do território ao qual a rede de atores sociais está instalada; onde a racionalidade seja conduzida pelo cálculo de consequências societárias, privilegiando as dimensões sócio-econômicoambientais (sustentáveis) para poder corrigir os equívocos provocados por um modelo de gestão que privilegia apenas critérios intraterritorias (para dentro do territorial), cuja base se apoia em racionalidade econômica de cálculo de consequências apenas territorial (SAMPAIO, 2015).

A ecossocioeconomia territorial não tem a pretensão de ser uma nova base conceitual para se pensar outro modo de vida, como sugere o ecodesenvolvimento. Porém, em que pese o fato de ser considerada uma teoria em construção, com quantidades reduzidas de produções científicas, tem-se a ambição de encampar a ecossocioeconomia como contributiva para se pensar alternativas plausíveis às problemáticas ambientais, sociais e econômicas, especialmente em nível territorial.

\subsection{O bem viver como paradigma de desenvolvimento}

\footnotetext{
${ }^{3}$ Capital social é um recurso de ação comunitária de um dado território (COLEMAN, 1990).
} 

e-ISSN 2016/Atual: 2525-7870 | e-ISSN 2015/2016: 2447-018X

As primeiras tentativas de se criar um "desenvolvimento alternativo" foram mudanças e ajustes para minimizar os custos sociais e ambientais e melhorar sua contribuição econômica. De acordo com Gudynas (2011) foram modificações de cunho instrumental. Na contramão do desenvolvimento, surgem então as chamadas "alternativas ao desenvolvimento", que passam, a discutir "[...] toda la base conceptual del desarrollo, sus modos de entender la naturaleza y la sociedad, sus instituciones, y sus defensas discursivas” (p. 392).

Assim, o conhecido conceito de "qualidade de vida" da sociedade de consumo entendido como uma simples acumulação de bens materiais, amplia-se para dimensões culturais afetivas, espirituais. Além disso, o componente ambiental é reconhecido no mesmo nível que aqueles referidos a qualidade de vida das pessoas. Nesta concepção será necessário assegurar a conservação da biodiversidade e manter os impactos humanos dentro da capacidade dos ecossistemas.

Neste discurso, surge um modelo de desenvolvimento chamado de Bem Viver/Vivir Bien/Buen Vivir (em aymara: suma qmaña, em kichwa: sumak kawsay, em guaraní: ñandareko). Esta forma de desenvolvimento aparece como uma categoria da filosofia de vida das sociedades indígenas ancestrais, estabelecendo uma cosmovisão diferente da ocidental, ao surgir de raízes comunitárias não capitalistas e se firmando nas novas constituições do Equador (aprovada em 2008) e Bolívia (2009).

A Constituição do Equador formalizou o reconhecimento dos direitos da Natureza, reconhecendo-a como sujeito (art. 72). Em paralelo, se manteve a postura clássica do direito a um ambiente saudável, focado nas pessoas. Na Constituição Boliviana, se mantém a figura clássica dos direitos cidadãos, qualidade e proteção ambiental, porém não existe um reconhecimento implícito dos direitos da natureza, mas sim direitos econômicos, sociais e culturais (Gudynas, 2011).

Art. 276. O regime de desenvolvimento tem os seguintes objetivos: 1. Melhorar a qualidade e expectativa de vida, aumentar as capacidades e potencialidades da população, no quadro dos princípios e direitos previstos na Constituição; [...] 4. Restaurar e conservar a natureza e manter um ambiente saudável e sustentável para garantir que as pessoas e as comunidades tenham permanente qualidade, água, ar e acesso à terra, e os benefícios dos recursos do subsolo e do patrimônio natural; [...] 7. Proteger e promover a diversidade cultural e respeitar seus espaços de lazer e de troca; recuperar, preservar e valorizar a memória social e patrimônio cultural (EQUADOR, 2008).

Para Acosta (2010), o bem viver é tanto uma proposta em construção, porque questiona o conceito ocidental do bem-estar, como uma proposta de luta, enfrentando a colonialidade do poder. Neste sentido, para atingir o bem viver, é essencial que haja participação ativa em 

e-ISSN 2016/Atual: 2525-7870 | e-ISSN 2015/2016: 2447-018X

espaços da comunidade e instituições locais (Macas, 2010). Ou seja, o bem viver da população depende do fortalecimento da participação na comunidade, incrementando a harmonia com a natureza e mantendo a soberania alimentar local.

Não se trata de continuar pelo caminho tradicional produtivista e sua visão mecanicista de crescimento econômico, mas buscar caminhos diferentes, mais ricos em conteúdos e por certo, mais completos e concretos. Neste contexto, o que se busca é uma economia que se sustenta na solidariedade, com outro tipo de relações de produção e cooperação. Para Acosta (2013):

El objetivo final es establecer un sistema económico sobre bases comunitarias y orientadas hacia la reciprocidad, que debe ser sustentable; es decir, debe asegurar procesos que respeten los ciclos ecológicos y que puedan mantenerse en el tiempo, sin ayuda externa y sin que se produzca una escasez crítica de los recursos (p.22).

Neste pressuposto, se abrem caminhos a possíveis transições para pensar outros desenvolvimentos, que exigem uma (des)construção do discurso colonial de poder (Quijano, 1997), questionando-se o caráter eurocêntrico dos saberes.

Más allá de la resistencia, la decolonialidad propone una postura ofensiva de intervención, transgresión y construcción. Una ofensiva que posibilita, viabiliza y visibiliza, por un lado, las concepciones, prácticas y modos de ser, estar, pensar y vivir de carácter decolonial actualmente existentes, haciendo que ellos abran procesos de enseñanza, des-aprendizaje y reflexión, no como nuevos modelos para ser reproducidos sino como bases para la deliberación, el cuestionamiento y el enfrentamiento con nosotros mismos y con las concepciones, prácticas y modos modernos, capitalistas, occidentales, y crecidamente alienantes -entre otros- del vivir cotidiano (WALSH, 2009, p. 234).

De outro lado fortalecer os princípios da interculturalidade que "[...] despeja horizontes y abre caminos que enfrentan al colonialismo aún presente, e invitan a crear posturas y condiciones, relaciones y estructuras nuevas y distintas" (WALSH, 2009, p.14). A interculturalidade significa o contato e intercâmbio entre culturas em términos equitativos. Deste modo, faz-se necessário e emergente refletir sobre a maneira que a interculturalidade e a (de)colonização do poder se faz necessária para que tenhamos um bem viver para todos.

\section{Metodologia}

Metodologicamente, trata-se de um ensaio bibliográfico que sistematiza um conjunto de esforços compreendidos entre revisão da literatura dos temas em questão e pesquisa de campo para apresentar uma análise comparativa que trata da mobilidade urbana, com foco no uso da 
bicicleta. O referencial teórico tem como base a pesquisa bibliográfica-exploratória com interpretação e análise crítica dos temas.

Trata-se de uma pesquisa exploratória de três casos reconhecidos no mundo e no Brasil: as cidades de Amsterdã (Holanda), Copenhague (Dinamarca) e Rio de Janeiro (Brasil). A coleta de dados baseou-se na observação de campo realizada nas regiões centrais e turísticas destas cidades que fazem uso da bicicleta com alternativa de locomoção tanto pelos moradores locais como pelos visitantes. Para a análise de indicadores ecossocioeconômicos utilizou-se como parâmetros atributos como: motivação para o uso da bicicleta; ações implementadas; níveis de investimentos; totalidade da infraestrutura cicloviária existente; política públicas de incentivo e educação para o uso da bicicleta; índice de sustentabilidade e projetos futuros sobre o modal cicloviária.

\subsection{Recorte da pesquisa}

\subsubsection{Rio De Janeiro (Brasil)}

A Lei Federal no. 12.587, de 3 de janeiro de 2012, instituiu as Diretrizes da Política Nacional de Mobilidade Urbana (PNMU) com o objetivo de integrar os diferentes modos de transporte e melhorar a acessibilidade e a mobilidade das pessoas e cargas no território dos municípios brasileiros. A PNMU trabalha com três macro objetivos: o desenvolvimento urbano, a sustentabilidade ambiental e a inclusão social (BRASIL, 2012).

Percebe-se que apesar da cultura do automóvel ser dominante, a política de incentivos ao uso da bicicleta nas capitais brasileiras e principalmente no Rio de Janeiro é resultado do reconhecimento dos numerosos benefícios ambientais e sociais que sua utilização pode proporcionar em áreas urbanas.

Entre as capitais brasileiras, o Rio de Janeiro é um dos principais centros social e cultural do país. Com um dos maiores PIB do Brasil e uma economia baseada no comércio, turismo, serviços, construção civil e indústria, conta atualmente com uma população estimada de 6.498.837 habitantes (residentes) e uma área de 1.200,179 Km 2 (IBGE, 2016).

A cidade recebeu seus primeiros 27 quilômetros de ciclovia na orla durante a preparação para a Conferência das Nações Unidas, sediada no Rio de Janeiro em 1992 (Eco-92) (BINATTI, 2016). Foi a partir deste ano que a bicicleta passou a ser reconhecida como um dos subsistemas de transporte da cidade e ganhou espaço em 1993 com a criação do Grupo de Trabalho para o planejamento e implantação do sistema cicloviário, o GT Ciclovias. O sistema cicloviário do Rio de Janeiro é formado por ciclovias, ciclofaixas, faixas compartilhadas e bicicletários. 
Ao concluir o Plano Estratégico de Governo para o período 2009-2012 e 2013-2016 o governo municipal do Rio de Janeiro alinhou as metas do setor de Transportes com as do Meio Ambiente. Nesse contexto foi criado o Programa "Rio, Capital da Bicicleta":

\begin{abstract}
[...] visando implementar ações de incentivo e fomento ao uso da bicicleta como importante modal de transporte complementar aos transportes de massa para pequenas e médias distâncias, promovendo a conservação e ampliação do sistema cicloviário municipal e a implantação de bicicletários nos pontos de maior demanda (PREFEITURA DA CIDADE do RIO de JANEIRO, 2014, p.4).
\end{abstract}

A meta era chegar a 2016 com uma malha cicloviária com 450 Km de extensão, e, para tanto, diversos órgãos públicos e agentes privados atuaram implementando esse sistema. Até este período, o Rio de Janeiro possuía a maior rede cicloviária da América Latina, com 432,5 quilômetros de ciclovia (RODRIGUES; ANDRADE; MARINO, 2016).

O Programa "Rio, Capital da Bicicleta" tem como objetivo a despoluição do ar do município e a Política Municipal sobre Mudanças Climáticas prevê que o planejamento do setor de transportes e de mobilidade urbana do município do Rio de Janeiro incorporem medidas de mitigação das emissões de gases de efeito estufa através da oferta de diferentes modais de transportes.

Entre os vários programas criados pela Prefeitura do Rio de Janeiro em parceria com o setor privado estava o projeto Pedala Rio - Sistema Alternativo para Mobilidade por Bicicletas de Aluguel - "SAMBA" no dia 11 de dezembro de 2008. Atualmente este projeto denomina-se Bike Rio. O sistema conta atualmente com 257 estações e contabiliza mais de 8 milhões de viagens (BINATTI, 2016).

A prefeitura por meio de campanhas educacionais e vídeos institucionais do uso da bicicleta, incentivando os pontos positivos, ligados à sustentabilidade e à saúde, para além dos ganhos efetivamente práticos em termos de custo e tempo nas pequenas e médias distâncias (RODRIGUES; ANDRADE; MARINO, 2016).

De acordo com dados divulgados pela Prefeitura do Estado do Rio de Janeiro (2014) foram registradas mais de 1,5 milhão de viagens em bicicleta por dia no Rio, tanto para pequenos deslocamentos como para o uso por parte do comércio na realização de entregas domiciliares e prestações de serviço.

A lógica do Plano Estratégico do Rio de Janeiro é pensar no longo prazo para agir no curto prazo. A revisão do Plano vigente define ações concretas que teve como horizonte os próximos quatro anos (2013-2016) representa um conjunto de aspirações para a cidade ao longo de um prazo muito mais extenso. Segundo a "Visão Rio 500 e Planejamento Estratégico 2017 
- 2020" pretende-se conservar e ampliar o sistema cicloviário municipal, integrando-o aos demais modais, implantando estações de guarda e empréstimos de bicicletas em vários pontos da cidade e fomentando a cultura do uso da bicicleta. O Objetivo é alcançar $585 \mathrm{~km}$ de malha cicloviária até 2020, implantando novos $135 \mathrm{~km}$ de ciclovias.

\subsubsection{Amsterdam (Holanda)}

Amsterdam é modelo no tema de mobilidade urbana sustentável, não se restringindo apenas ao uso da bicicleta por parte da população local, mas também ao visitante. Tal iniciativa faz Amsterdam ser reconhecida mundialmente, e a bicicleta faz parte da identidade nacional e do imaginário social.

O uso intensivo da bicicleta é decorre da variedade de políticas de transporte de uso amigável. O eficiente sistema de mobilidade permite uma convivência pacífica no trafego entre os usuários de carro, bicicleta, pedestre e turista, sendo normatizado pela legislação de trânsito do país.

A cidade possui $400 \mathrm{~km}$ de ciclovias, com sinais de trânsito exclusivo. Alguns percursos se constituem como atalhos quando se compara a outras soluções motorizadas e são realizados com segurança e rapidez. Bairros residenciais restringem os limites de velocidade dos automóveis para 30 quilômetros por hora para melhorar a segurança. As facilidades de estacionamento das bicicletas estão em toda a cidade, enquanto o estacionamento de veículos no centro é muito restrito e oneroso.

Os habitantes de Amsterdam ao longo de 2005 e 2007 usaram mais suas bicicletas, em média, 0,87 vezes por dia. Esta foi a primeira vez que seu uso ultrapassou a do automóvel. No centro da cidade a bicicleta é utilizada na maioria das vezes. Isso pode ser em decorrência dos planos de estacionamento restritivos que vigora desde a década de 1990, das políticas adotadas ao longo dos últimos 30 anos para tornar o uso da bicicleta mais atraente e seguro, além de políticas de desestímulo do uso do automóvel na cidade (WORLDWATCH INSTITUTE, 2015).

O governo investiu cerca de 76 milhões de dólares em projetos viários para bicicleta em Amsterdã, entre 2007 e 2010, uma média de 13 euros por residente. Estes investimentos estimularam que mais usuários utilizem a bicicleta. A expectativa é que quanto mais ciclistas nas ruas, menor será a taxa de acidentes (WORLDWATCH INSTITUTE, 2015).

O cicloturismo na Holanda é considerado uma atividade turística que movimenta a economia e promove mudanças significativas na sociedade e na cultura de compartilhamento do espaço público. Esta modalidade de transporte representa uma proposta inovadora, à medida em que turistas, na maioria das situações, optam por visitar espaços de forma mais descontraída 
(HOLANDA, 2014). Para isso a cidade dispõe do serviço de aluguel de bicicletas em vários pontos. A maioria é ofertada por empresas de hospedagem. Há ampla gama de excursões e city tours que se utilizam bicicleta, com a finalidade de conhecer e perceber a cidade de maneira mais próxima.

Amsterdã esta interconecta a outras cidades do país, por meio de uma rede de ciclovias nacionais, o que demonstra a predominância do ciclismo como esporte e meio de transporte. $\mathrm{O}$ clima e o território plano contribuem para que a bicicleta seja preferida no momento de selecionar o modal para deslocamento.

\subsubsection{Copenhague (Dinamarca)}

A política de transporte dinamarquesa chegou a um ponto de inflexão entre as décadas de 70/80, quando o país deu início ao planejamento urbano que previa a criação de infraestrutura específica de ciclismo e para o slow traffi.

Possui ao redor de 350 quilômetros de ciclovias com mão dupla em todas as principais vias da cidade (com ciclo faixas). A cidade de Copenhague tem como meta reduzir $20 \%$ das emissões de carbono até 2015 e ser a primeira cidade do mundo em neutralizar $100 \%$ o carbono até 2025, tendo como principal estratégia estimular as pessoas a utilizar bicicleta (DANISH ROAD DIRECTORATE, 2015).

Para alcançar este desafio alguns dados apontam que Copenhague está no caminho certo onde: $90 \%$ da população possuem pelo menos uma bicicleta e, apenas $29 \%$ das famílias possui um carro; $58 \%$ usam bicicleta diariamente para fazer pequenos traslados. Serviços do governo, como correios e polícia, se utiliza de bicicletas, e deixa de emitir cerca de 90.000 toneladas de $\mathrm{CO}_{2}$ a cada ano (DANISH ROAD DIRECTORATE, 2015).

As ciclovias possuem calçada elevada "curbstone" o que gera uma proteção em relação a circulação de veículos. O padrão das ciclovias determina que a largura da pista deva ser de 2,5 a 2,8 metros o que oferece espaço para três ciclistas lado a lado.

Observando as vias da cidade, sobretudo o comportamento dos motoristas, provavelmente este contribua para que as taxas de acidentes com os ciclistas sejam baixas. Quatro de cada cinco indivíduos, entre eles motoristas, possuem uma bicicleta, o que sugere que estejam acostumados a compartilhar o espaço público com as bicicletas.

O turista que deseja alugar uma bicicleta se sentirá seguro para circular e conhecer os atrativos turísticos em Copenhague. Os cruzamentos são todos sinalizados para carros, pedestres e ciclistas, além de alguns deles possuírem mecanismo de alerta aos motoristas quando ciclistas estão se aproximando. Passeios de bicicleta são econômicos autoguiados. 
Não é totalmente claro como e por que as taxas de acidentes mudam à medida que o número de ciclistas varia, mas a segurança melhora em uma cidade a mediada em que o número de ciclistas aumenta. Este efeito tem sido observado em estudos na Dinamarca, Países Baixos, 14 outros países europeus, Austrália e 68 cidades da Califórnia (THE GUARDIAN, 2014).

Em Copenhague a parceria público-privada fez surgir um programa de compartilhamento de bicicleta, intitulado City Bike, que oferece um serviço de aluguel de bicicletas a um preço acessível, em torno de $25 \mathrm{kr}$ (US\$3,60) por hora e acompanha global positioning system, (GPS). O turista pode alugar a bicicleta e devolvê-la em qualquer das 120 estações disponíveis em toda a cidade.

O sistema de compartilhamento de bicicleta tem muitas vantagens e funciona como parte integrada do sistema de transporte público, de modo que mais viajantes possam escolher uma forma sustentável de transporte. O sistema fortalece a imagem de responsabilidade socioambiental da cidade e facilita a locomoção não só dos moradores, mas também dos turistas.

Para facilitar a locomoção dos usuários (morador local e turista), aliando bicicleta e transporte público, há estacionamento de bicicletas nas estações de trem. A Estação Central Oesterport de Copenhague, por exemplo, oferece estacionamento pago de bicicletas coberto e fechado.

Pelas ciclovias e ciclo faixas o morador local e turista podem conhecer monumentos, como Rosenborg Castle, The Little Mermaid, além de museus, praias e parques de diversão. As bicicletas são permitidas em trens locais e regionais, basta comprar um bilhete para transportála. No metrô, no entanto, não são permitidas durante as horas de maior movimento.

\section{Estudo de caso}

\subsection{Comparando as experiências}

De acordo com Gonzalo-Orden et al., (2014), o uso da bicicleta tem aumentado nos últimos anos em decorrência da introdução, desenvolvimento ou expansão das redes de ciclovias, e das instalações de estacionamento para bicicletas. Assim, para análise das experiências utilizaram-se indicadores ecossocioeconômicos que analisam a gênese ou problema que motivaram o desenvolvimento da mobilidade urbana por meio da bicicleta; as ações implementadas que visam garantir a efetividade dos projetos de mobilidade urbana por 

e-ISSN 2016/Atual: 2525-7870 | e-ISSN 2015/2016: 2447-018X

ciclovias, ciclorotas e ciclofaixas; os níveis de investimentos que garantam efetivada e possibilitem novos projetos; a totalidade da infraestrutura cicloviária existente em cada uma das cidades pesquisadas; as política públicas de incentivo e educação para o uso da bicicleta; o índice de sustentabilidade do modal e os projetos futuros que visam ampliar ou melhorar a infraestrutura existente.

A problemática (Tabela 1) dos projetos analisados está correlacionada à dinâmica da mobilidade urbana. As experiências têm sua gênese impulsionada pela crise do petróleo deflagrada na década de 1970 e, da percepção da dependência do combustível fóssil em todo mundo. Coadunam a esta crise, consequências que o progresso técnico e o crescimento econômico desenfreado estavam causando ao meio ambiente e a inclusão dos problemas ambientais na agenda do desenvolvimento das nações e das relações internacionais como um todo.

Tabela 01 - Gênese/ problema que motivou ações de uso da bicicleta

\begin{tabular}{|c|c|c|}
\hline Rio de Janeiro & Amsterdam & Copenhague \\
\hline $\begin{array}{l}\text { A partir da Conferência das Nações Unidas, } \\
\text { sediada no Rio de Janeiro em } 1992 \text { a bicicleta } \\
\text { passou a ser reconhecida como um dos } \\
\text { subsistemas de transporte da cidade e ganhou } \\
\text { espaço em } 1993 \text { com a criação do Grupo de } \\
\text { Trabalho para o planejamento e implantação } \\
\text { do sistema cicloviário, o GT Ciclovias. }\end{array}$ & $\begin{array}{l}\text { Década de } 1970 / 80 \text {, o país deu } \\
\text { início ao planejamento urbano } \\
\text { que previa a criação de } \\
\text { infraestrutura específica de } \\
\text { ciclismo e para o "tráfego } \\
\text { calmo". }\end{array}$ & $\begin{array}{l}\text { Em } 1978 \text { a crise do petróleo evidenciou } \\
\text { a dependência do país pelo } \\
\text { combustível o que fez o governo tomar } \\
\text { medidas e gerar uma política estatal } \\
\text { para promoção da bicicleta como meio } \\
\text { de transporte }\end{array}$ \\
\hline
\end{tabular}

Fonte: Os autores, 2015.

A partir de então, os países buscaram modais que pudessem ser alternativas de transporte autossuficiente. As principais ações adotadas sendo apontadas como determinantes no sucesso das experiências, em quase todas as grandes cidades mundiais, foi à implantação de políticas de incentivo de uso da bicicleta para mobilidade urbana, tendo como vantagem o preço acessível do bem, ser um meio de transporte não poluente, que promove a equidade social e a qualidade de vida.

Ações como a criação de infraestrutura local, campanhas de educação para o uso da bicicleta, combinação do uso da bicicleta e transporte público, redução do acesso de automóveis ao centro da cidade e encarecimento do estacionamento, redução do espaço vial destinado aos automóveis, redução da velocidade dos automóveis na maioria das vias urbanas centrais a 30 ou $40 \mathrm{~km} / \mathrm{h}$, promoveu o uso da bicicleta na cidade de Amsterdam. Em Copenhague foi criado o slogan "Copenhague cidade da bicicleta" o que estimulou a população ao uso da bicicleta. 
Foram feitos investimentos em infraestrutura local; campanhas de educação para o uso da bicicleta, combinação do uso da bicicleta e transporte público, estacionamento, sinalização e vias elevadas para a circulação do modal.

No Rio de janeiro a rede cicloviária conta com 432,5 quilômetros de ciclovia é insuficiente e ainda não configura um sistema integrado com os transportes de massa, embora se tenha algumas rotas cicloviárias cujo destino são as estações de Transporte Rápido por Ônibus - BRT em inglês (Bus Rapid Transit) metrô, barcas e trens. Desse modo, é necessário consolidar a implantação de um sistema cicloviário que tenha interligação com as estações de transportes de massa, os equipamentos urbanos e os centros de comércio, serviços e lazer. Os bicicletários existentes nos logradouros públicos também são insuficientes.

A política de investimentos, em Amsterdam e Copenhague se assemelha, e as aplicações visam à melhoria de vias, segurança, estacionamento e campanhas educativas. Os reajustes são anuais e giram em torno de U\$ 26 per capita. Outros valores também são aplicados. Em Amsterdam de acordo com o Summary Long-Term Bicycle Plan 2012-2016, estão previstos investimentos na ordem de 134 milhões de dólares no período, para que os usuários possam continuar a usufruir dos benefícios do transporte de bicicleta. Em Copenhague os investimentos têm demonstrado impacto sociocultural significativo (THE SECRETARIAT CYCLING EMBASSY OF DENMARK, 2015).

No Rio de Janeiro a partir do Planejamento Estratégico 2017 - 2020 pretende-se conservar e ampliar o sistema cicloviário municipal, integrando-o aos demais modais, incentivando o uso de bicicletas em vários pontos da cidade. O Objetivo é alcançar $585 \mathrm{~km}$ de malha cicloviária até 2020, implantando novos 135 km de ciclovias.

Sobre campanhas educativas, Amsterdam e Copenhague possuem ações institucionais na educação básica, envolvendo professores, pais e crianças. No Rio de Janeiro, a prefeitura por meio de campanhas educacionais e vídeos institucionais do uso da bicicleta, incentiva os pontos positivos, ligados à sustentabilidade e à saúde, para além dos ganhos efetivamente práticos em termos de custo e tempo nas pequenas e médias distâncias.

Em todas as cidades são previstos investimentos para ampliação e melhoria das ciclovias e ciclo faixas. Projetos para novas instalações de estacionamento, melhoria do fluxo também são apontados. Atenção especial é dada a necessidade de melhorar a segurança do ciclista e promover o respeito por parte dos motoristas. A inovação acontece em Amsterdam onde um esquema recentemente prevê a construção de um maciço debaixo d'água, adjacente à estação de Central da cidade e que serve como zona portuária de Amsterdam, com capacidade para estacionar 7.000 bicicletas. Túneis conectariam a garagem diretamente para o metrô e da 
estação ferroviária Central, ao centro de trânsito mais movimentado da cidade (MOTHER NATURE NET WORK, 2015).

Com relação ao uso do modal para o desenvolvimento do turismo em Amsterdam e Copenhague se encontra consolidado, fornecendo ao visitante completa infraestrutura de cicloturismo. No Rio de Janeiro além da ampliação da malha cicloviária e implantação de 135 $\mathrm{Km}$ de ciclovias, ciclofaixas e/ou faixas compartilhadas com 4 mil bicicletários nos pontos de maior demanda, outra medida é uniformizar e recuperar o sistema cicloviário quanto aos padrões de sinalização horizontal e vertical e a utilização de materiais mais duráveis e adequados.

Os indicadores de sustentabilidade (Tabela 2) que demonstram o sucesso dos projetos em termos de monitoramento do uso da bicicleta apontam a diminuição de emissões de CO2 nas cidades de Amsterdam e Copenhague.

Tabela 2 - Índice de sustentabilidade do modal

\begin{tabular}{|c|c|c|}
\hline Rio de Janeiro & Amsterdam & Copenhague \\
\hline $\begin{array}{l}\text { O Programa "Rio, Capital da Bicicleta" tem como } \\
\text { objetivo a despoluição do ar do município e a } \\
\text { Política Municipal sobre Mudaças Climáticas } \\
\text { prevê que o planejamento do setor de transportes e } \\
\text { de mobilidade urbana do município do Rio de } \\
\text { Janeiro incorporem medidas de mitigação das } \\
\text { emissões de gases de efeito estufa através da oferta } \\
\text { de diferentes modais de transportes. }\end{array}$ & $\begin{array}{l}\text { Com mais de } 500.000 \text { bicicletas } \\
\text { na cidade, o governo municipal } \\
\text { investiu em edifícios } \\
\text { municipais neutros de } \mathrm{CO} 2 \text { e } \\
\text { considera reduzir ainda mais } \\
\text { para tornar-se líder em termos } \\
\text { de redução. }\end{array}$ & $\begin{array}{l}\text { Reduziu cerca de } 90.000 \\
\text { toneladas de emissões de CO2 } \\
\text { por ano, mais de } 50 \% \text { da } \\
\text { população da cidade usa a } \\
\text { bicicleta como transporte para o } \\
\text { trabalho todos os dias. }\end{array}$ \\
\hline
\end{tabular}

Fonte: Os autores, 2015.

Em relação aos projetos futuros (Tabela 3), são observadas estratégias que possibilitem a ampliação do sistema, sua integração com outros modais, ampliação nos parques de estacionamento, melhoria na segurança e promover campanhas de visem a convivência entre ciclista e motoristas.

Tabela 3 - Projetos Futuros

\begin{tabular}{|c|c|c|}
\hline Rio de Janeiro & Amsterdam & Copenhague \\
\hline $\begin{array}{l}\text { Planejamento estratégico 2017-2020 onde } \\
\text { pretende-se conservar e ampliar o sistema } \\
\text { cicloviário municipal, integrando-o aos demais } \\
\text { modais, implantando estações de guarda e } \\
\text { empréstimos de bicicletas em vários pontos da } \\
\text { cidade e fomentando a cultura do uso da bicicleta. } \\
\text { O Objetivo é alcançar } 585 \mathrm{~km} \text { de malha cicloviária } \\
\text { até } 2020 \text {, implantando novos } 135 \mathrm{~km} \text { de ciclovias, } \\
\text { ciclofaixas e/ou faixas compartilhadas. }\end{array}$ & $\begin{array}{l}\text { Plano ciclista de longo prazo que } \\
\text { considera a construção de } 7000 \\
\text { estacionamentos embaixo da } \\
\text { água, } 4000 \text { sobre a água e avançar } \\
\text { na meta de ter } 40 \text { mil novos } \\
\text { estacionamentos e novas medidas } \\
\text { de curto prazo para resolver o alto } \\
\text { fluxo de ciclistas até } 2030 \text {. }\end{array}$ & $\begin{array}{l}\text { Ampliar } 65 \mathrm{~km} \text { de ciclovias até } \\
\text { 2016, melhorar instalações dos } \\
\text { estacionamentos de bicicletas; } \\
\text { implementar campanhas para } \\
\text { seu uso; segurança; } \\
\text { desenvolver uma campanha } \\
\text { que vise diminuir as tensões } \\
\text { entre ciclista e motorista. }\end{array}$ \\
\hline
\end{tabular}

Fonte: Os autores, 2015. 
Analisando os dados coletados e com base em estudos realizados por Gonzalo-Orden et al., (2014) pode-se concluir que para garantir alternativas de mobilidade urbana não é suficiente ter muitos quilômetros de uma rede cicloviária, mas tê-la com melhor qualidade. Deve ser segura, conectada, acessível, direta, atraente, conveniente, integrada com o sistema de transporte público, com interseções adaptadas ao estacionamento de bicicleta logicamente localizadas e projetadas para garantir a segurança do usuário e coibir o roubo das bicicletas. Se uma cidade atende a esses requisitos, estará pronta para oferecer este modo de transporte de forma sustentável (GONZALO-ORDEN et al., 2014), garantido qualidade de vida e promovendo o bem viver urbano, a partir da mobilidade.

\subsection{Mobilidade urbana como princípio ecossocioeconômico e de bem viver}

As possibilidades reais de viver em comunidade, parte essencial do "bem viver", passam primeiro pela possibilidade de que, para construir essa comunidade, será necessário desconstruir as ideias dominantes sobre Estado, economia, educação, superando a colonialidade constitucional, para assentar-se nas bases de uma comunidade política inclusiva e democrática, que permitirá nutrir-nos de cosmovisões, saberes, epistemologias e práticas culturais diversas.

As cidades sempre representaram o modelo de reprodução dos modos de vida colonialistas, modernos, consumistas e capitalistas. O imaginário que se formou das cidades é o estereótipo de uma civilização superior e detentora do conhecimento, em detrimento do rural, considerado atrasado.

De outro lado, com o processo de modernização, as cidades cresceram acima de sua capacidade e serviços básicos como água, energia elétrica, moradia, educação, saúde e transporte tornaram-se escassos. Nossas cidades perderam as singularidades e se transformaram em centros de consumo (IBÁNEZ, 2013).

A mobilidade urbana é o grande desafio das cidades contemporâneas. Impactos decorrentes de fluxos do transporte de carga: entrada, saída, demanda e consumo que não organizadas geram poluição, congestionamentos e, também, acidentes no trânsito. Diante disso observa-se crescente debate sobre modais de transporte sustentáveis e sua relação com o uso de transporte coletivo para o deslocamento diário da população. Cidades, independentemente de seu porte, exercem um efeito de aglomeração das diversificadas atividades econômicas, que no cotidiano, interferem no deslocamento entre residência e trabalho. O planejamento e a gestão integrada do sistema de transporte e da diretriz de uso e ocupação do solo são aspectos essências para promover cidades sustentáveis, focadas também na mobilidade urbana. 
No setor de transportes se desenvolveram formas de logística de transporte por meio do modal rodoviário realizado por caminhões, símbolo do transporte de cargas, cujo uso indiscriminado de combustível, água e energia é dispendioso e a emissão de poluentes prejudiciais à saúde. Estes elementos sustentam a cidade e o sistema capitalista como se fosse a única modalidade possível na distribuição de mercadorias.

A mobilidade urbana pensada como condição para o bem viver nas cidades deve, de acordo com o Ministério das Cidades (2007) ser o resultado de um conjunto de políticas de transporte e circulação que visam dar acesso amplo e democrático ao espaço urbano, por meio da priorização de modos de transporte coletivo e não motorizados, de maneira efetiva, socialmente inclusiva e ecologicamente sustentável.

Contudo, o acesso ao transporte coletivo de qualidade, saúde, educação, segurança e outros serviços básicos estão se tornando deficitários em muitas cidades que tem seu desenvolvimento econômico, de acordo com Macário (2005) diretamente afetado pela qualidade da mobilidade, podendo atrair ou afastar pessoas, investidores, indústrias e empregos.

Entretanto, destacam-se formas mais eficientes de transporte, em particular no que se refere ao transporte de cargas e de entregas: o transporte sob duas rodas. Neste sentido, pensar em alternativas de bem viver que ressignifiquem a vida na cidade é considerar formas mais eficientes, econômicas e menos poluentes de logística urbana (níveis de emissões de CO2, poluição sonora, congestionamento e outros), realizados com bike messenger e motoboy.

Assim, muitas cidades mundiais têm adotado o sistema de transporte sobre duas rodas como alternativa sustentável de mobilidade urbana, onde os usuários, independentemente de sua classe econômica e social, fazem uso do modal, garantido qualidade de vida e economia na sua locomoção diária (GRIMM et al., 2015), e promovendo o bem viver nas cidades.

Não se trata de pensar em novos projetos de logística urbana, senão em um modelo de mobilidade que exige uma capacidade de (re)configurar e (re)pensar novos modos de vida, mais sustentáveis. Ou seja, novas maneiras de nos relacionarmos com o meio ambiente com mais equidade e harmonia, como uma forma de (des)contruir a lógica do desenvolvimento ilimitado.

\section{Conclusões}

Diante do objetivo de dialogar sobre o tema da ecossocioeconomia a partir da relação dialética do bem viver e apresentar uma análise comparativa que trata da mobilidade urbana, com foco no uso da bicicleta, chegaram-se a algumas convergências e divergências entre as cidades analisadas. 

e-ISSN 2016/Atual: 2525-7870 | e-ISSN 2015/2016: 2447-018X

Contemporaneamente, experiências em curso sinalizam para a possibilidade de se pensar em alternativas de desenvolvimento baseados em princípios ecossocioeconômicos e do bem viver. Cidades como Rio de Janeiro, Amsterdã e Copenhague são indicativos de que outros modais de transporte são viáveis e podem ser uma resposta a necessidade de mobilidade urbana sustentável, por meio da promoção de políticas públicas que incentivem o uso da bicicleta como meio de locomoção.

Entretanto, deve-se ter claro que a ecossocioeconomia não tem a pretensão de ser uma nova base conceitual para se pensar outro modo de vida, mas sim uma teoria em construção, que acampa experiências paradigmáticas, como pode ser o uso da bicicleta como alternativa de transporte urbano, que contribuam para se pensar alternativas plausíveis às problemáticas ambientais, sociais e econômicas, especialmente em nível territorial.

Rio de Janeiro, Amsterdam e Copenhague apresentam políticas de mobilidade urbana que representam mudança de paradigma de um sistema de transporte motorizado para cicloviário, em consonância com a conservação do meio ambiente e a promoção do desenvolvimento. Porém, Amsterdam e Copenhague iniciaram o processo de mobilidade urbana por meio de um planejamento urbano e ambiental na década de 1970, enquanto que no Rio de Janeiro a mobilidade urbana só ganhou espaço com a Conferência das Nações Unidas, sediada no Rio de Janeiro em 1992.

Percebe-se igualmente que Amsterdam e Copenhague investiram não somente na mobilidade urbana com o uso de bicicletas, mas em edifícios sustentáveis, redução de $\mathrm{CO} 2$ e na educação sistemática da população por meio de campanhas educativas, fazendo com o uso de bicicleta superasse o uso de automóveis.

No Rio de Janeiro apesar da ampliação da malha cicloviária ser a maior da América Latina e da construção de infraestruturas e grandes projetos de transporte, que buscam reorganizar o sistema de mobilidade intraurbana, o uso da bicicleta ainda é menor que a circulação de automóveis, o que demanda de mais campanhas educativas. Soma-se a estas questões da insegurança do ciclista no trânsito, qualidade da infraestrutura da malha viária e falta de integração intermodal que é um projeto idealizado no planejamento estratégico 20172020.

Porém, a criação de infraestrutura e políticas de mobilidade urbana é importante, mas são apenas alguns dos elementos no desenvolvimento de uma cidade para o bem viver. Ela deve passar pelo planejamento e gestão integrada do sistema que compõe a cidade e das diretrizes de uso e ocupação do solo. 
Neste contexto, indica-se que os esforços e políticas de mobilidade urbana devem estar voltados a mudança de percepção do cidadão em respeito aos benefícios ecossocioeconômicos do modal. Estes aspectos transpõem as questões meramente voltadas ao transporte, impactando na melhoria da qualidade de vida e saúde, na redução da emissão de poluentes atmosféricos e sonoros e na redução de impacto paisagístico sobre o território.

Entretanto, estas ações exigem esforços no sentido de construir um futuro inclusivo, sustentável e resiliente para pessoas e o planeta. Para que o desenvolvimento seja sustentável e inclusivo, é fundamental harmonizar três elementos principais: crescimento econômico com justa distribuição de seus benefícios; participação das comunidades na tomada de decisão e criação de políticas públicas e, a proteção ambiental. Esses elementos estão interligados e todos são essenciais para promover a diminuição das desigualdades, redução da pobreza e ao mesmo tempo promover o bem viver nas cidades.

\section{Referências}

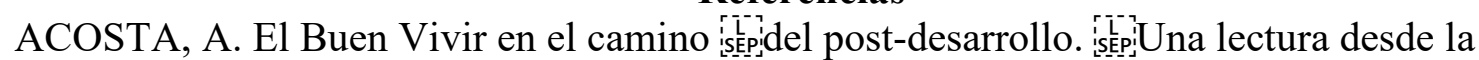
Constitución de Montecristi. Policy Paper 9. Fundación Friedrich Ebert, FES-ILDIS. Ecuador: octubre, 2010.

ACOSTA, A. Otra economia para outra civilização. 2013: Temas 75: 21-27.

BINATTI, G. Mobilidade de Cultura de Bicicleta no Rio de Janeiro. Transporte Ativo: Rio de Janeiro, 2016.

BRASIL. Lei N. 12.587 de 03 de janeiro de 2012. PNMU - Política Nacional de Mobilidade Urbana. Disponível em http://www.planalto.gov.br/ccivil_03/_ato20112014/2012/lei/112587.htm. Acesso em 31 de maio de $201 \overline{7}$.

COLEMAN, J. S. Foundations of social theory. Cambridge: Harvard University Press, 1990.

COSTA, M. S. Um Índice de Mobilidade Urbana Sustentável. Tese de Doutorado. Escola de Engenharia de São Carlos da Universidade de São Paulo. São Carlos, 2008.

DANISH ROAD DIRECTORATE. Collection of Cycle Concepts. Danish Road Directorate, 2000. Disponível em: http://www.cities-for-cyclists.org/dokumenter/cyccon.pdf. Acesso em: 02 de abril de 2015.

EQUADOR. Constitución Política de La República del Ecuador. 2008. Disponível em: $<$ http://pdba.georgetown.edu/Constitutions/constudies.html $>$. Acesso em: 29 de maio de 2017.

FALU, A.; MARENGO, C. Las políticas urbanas: desafíos y contradicciones. CLASCO. E1 rostro urbano de América Latina. Buenos Aires, 2004. 
GTZ Sustainable Urban Transport Project - GIZ SUTP. GTZ, Eschborn-Alemanha, 2011. Disponível em: www.sutp.org. Acesso em 23 de março e 2015.

GRIMM, I. J.; SAMPAIO. C. A. C.; SEGOVIA, Y. M. Mobilidade Urbana Sustentável e o Turismo: Análise Comparativa Brasil, Holanda e Dinamarca. Anais do XIII Encontro da Associação Nacional de Pesquisa em Pós-graduação em Turismo - ANPTUR. 2015. Disponível em: http://www.anptur.org.br/anptur/anais/v.11/DPS3_pdf/177.pdf. Acesso em 03 de maio de 2017.

GONZALO-ORDENA, H.; LINARESA, A.; VELASCOA, L.; DÍEZA, J.M.; ROJOA, M. Bikeways and cycling urban mobility. Procedia - Social and Behavioral Sciences. 2014, p. $567-576$.

GRIMM, I. J. FREDER, S. M.; SAMPAIO, C. A.C.; PROCOPIUCK, M. Arranjos socioprodutivos de base territorial: uma análise das feiras livres comunitárias na cidade de Curitiba (PR). Anais do VI Encontro de Turismo de Base Comunitária e Economia Solidária. Bahia, 2016.

GUDYNAS, E. Buen vivir: Germinando alternativas al desarrollo. América latina em movimiento, ALAI, N. 462: 1-20, febrero 2011, Quito.

GUDYNAS, E. Más allá del nuevo extractivismo: transiciones sostenibles y alternativas al desarrollo. En: El desarrollo en cuestión. Reflexiones desde América Latina. Fernanda Wanderley, coordinadora. Oxfam y CIDES UMSA, La Paz, Bolivia, 2011, p.379-410.

GUTH, D. Migração modal: por que estamos perdendo ciclistas diariamente. In: Mobilidade por bicicleta no Brasil. Org. ANDRADE, V.; RODRIGUES, J.; MARINO, F.; LOBO, Z. Rio de Janeiro: PROURB/UFRJ, 2016, p. 239 -265.

HOLANDA. Fundação Embaçada Holandesa do ciclismo. 2014. Disponível em: http://www.nlgovlim.com/semanaholandesa/?p=bike. Acesso em: 17 de agosto. 2014.

IBÁÑEZ, M. R. Resignificando la ciudad colonial y extractivista. En: Miriam Lang, Claudia López y Alejandra Santillana. Alternativas al capitalismo. Colonialismo del siglo XXI. Grupo Permanente de Trabajo sobre Alternativas al Desarrollo. Ediciones Abya Yala. Quito, Ecuador: 2013.

IBGE - Instituto Brasileiro de Geografia e Estatística. Cidades 2016. Disponível em: http://cidades.ibge.gov.br/xtras/perfil.php?codmun=330455. Acesso em 01 de junho de 2017.

KAPP, K. W. Social costs of private enterprise. Cambridge, Massachusetts. Harvard. University Press: 1950.

MACAS, L. Sumak Kawsay. La vida en plenitud. América Latina en Movimiento, $\mathrm{N}^{\mathrm{o}} 452$, 2010, p. 14-16.

MACÁRIO. M, R, M, R. Quality Manangement in Urban Mobility Systems: an Integrated Approach. Tese de Doutorado - Instituto Superior Técnico, Universidade Técnica de Lisboa, Lisboa, 2005. 
MINISTERIO DAS CIDADES. POLITICA NACIONAL DE MOBILIDADE URBANA, SEMOB - Secretaria Nacional de Transportes e da Mobilidade Urbana. Disponível em: http://www.emdec.com.br/eficiente/repositorio/6489.pdf. Acesso em: 10 de maio de 2014.

MOTHER NATURE NET WORK. Amsterdam mulls underwater bike garage as available parking for cyclists dwindles. Disponível em: http:/www.mnn.com/greentech/transportation/blogs/amsterdam-mulls-underwater-bike-garage-as-available-parkingfor\#ixzz3a93CHlno. Acesso em 07 de março de 2015.

ORNÉS, S. La Gestión Urbana Sostenible: Algunos componentes necesarios de entender. Universidad Simón Bolívar. División de ciencias sociales y humanidades, departamento de planificación urbana, 2012.

PEREIRA, M.G. B. G. dos S. Mobilidade por bicicleta em Salvador/Bahia: liberdade e liberação. In: Mobilidade por bicicleta no Brasil. Org. ANDRADE, V.; RODRIGUES, J.; MARINO, F.; LOBO, Z. Rio de Janeiro: PROURB/UFRJ, 2016, p.211-237.

PREFEITURA DA CIDADE DO RIO de JANEIRO. Caderno de Encargos para execução de projetos cicloviários. Rio de Janeiro, junho de 2014. Disponível em: http://www.rio.rj.gov.br/dlstatic/10112/91265/4124033/CADERNO.DE.ENCARGOS.FINAL .062014.pdf. Acesso em: 01 de junho de 2017.

PREFEITURA DA CIDADE DO RIO DE JANEIRO. O Rio do amanhã - Visão Rio $500 e$ Planejamento Estratégico 2017 - 2020. Disponível em: file://Users/liliane/Downloads/bookplanejamento-estrategico.pdf. Acesso em 01 de junho de 2017.

POLANY, M. The tacit dimension. Gloucester (Mass.): Peter Smith, 1983.

QUIJANO, A. Colonialidad del poder, cultura y conocimiento en América Latina. Anuario Mariateguiano. ix/9: 113-121, 1997.

RODRIGUES; ANDRADE; MARINO, 2016. Mobilidade por bicicleta no Rio de Janeiro: quem são os ciclistas, porque e como pedalam. In: Mobilidade por bicicleta no Brasil. Org. ANDRADE, V.; RODRIGUES, J.; MARINO, F.; LOBO, Z. Rio de Janeiro: PROURB/UFRJ, 2016, p. 169-189.

SAMPAIO, C. A. C. (org.). Gestão que privilegia uma outra economia: ecossocioeconomia. Blumenau, SC: Edifurb, 2010.

SAMPAIO, C. A. C. Cities and solution: urban ecosocioeconomics. Pullman, Washington: Washington State University, Fulbright Foundation, 2015. Report.

SAMPAIO, C. A. C.; PARKS, C.; GRIMM, I.; ALCANTÂRA, L.; FERNANDES, V. Ecossocioeconomia: análise de experiências ao Oeste dos Estados Unidos da América. Revista Brasileira de Gestão e Desenvolvimento Regional. Prelo. 2017.

THE GUARDIAN. Quais são as cidades mais seguras para os ciclistas no mundo? Disponível em: http://www.theguardian.com/lifeandstyle/2013/nov/20/how-safe-are-worldscities-for-cyclists. Acesso em 20 de abril de 2015. 

e-ISSN 2016/Atual: 2525-7870 | e-ISSN 2015/2016: 2447-018X

THE SECRETARIAT CYCLING EMBASSY OF DENMARK. About the Cycling

Embassy. Disponível em: http://www.cycling-

embassy.dk/about_cycling_embassy_of_denmark/about-the-cycling-embassy/. Acesso em: 16 de março $\overline{d e} 2015$.

WORLDWATCH Institute. In Amsterdam, the Bicycle Still Rules, 2015. Disponível em: http://www.worldwatch.org/node/6022. Acesso em 13 de abril de 2015.

WALSH. C. Interculturalidad, estado, sociedad: luchas (de)coloniales de nuestra época. Primera edición: Universidad Andina Simón Bolívar / Ediciones Abya-Yala, Quito, marzo 2009. 253p. 